\title{
Coulisses
}

Revue de théâtre

42| Printemps 2011

Racine : Théâtre et émotion

\section{Racine : théâtre et émotion}

John Campbell

\section{(2) OpenEdition}

Journals

Édition électronique

URL : https://journals.openedition.org/coulisses/568

DOI : 10.4000/coulisses.568

ISSN : 2546-9460

\section{Éditeur}

Presses universitaires de Franche-Comté

\section{Édition imprimée}

Date de publication : 15 février 2011

Pagination : 13-16

ISBN : 978-2-84867-316-5

ISSN : 1150-594X

Référence électronique

John Campbell, «Racine : théâtre et émotion », Coulisses [En ligne], 42 | Printemps 2011, mis en ligne le 30 novembre 2016, consulté le 29 décembre 2022. URL : http://journals.openedition.org/coulisses/ 568 ; DOI : https://doi.org/10.4000/coulisses.568 


\title{
Racine : théâtre et émotion
}

\author{
JOHN CAMPBELL \\ Professeur à l'Université de Glasgow
}

Racine, auteur dramatique ? La question peut et doit choquer. Elle n'en mérite pas moins d'être posée. Car «Racine» est devenu tellement plus, ou peutêtre tellement moins : monument national, icône du classicisme le plus sévère, devenu surtout un objet d'érudition pour universitaires et de crainte pour les lycéens, si tant est que les pièces de Racine soient encore étudiées au lycée.

Comment en sommes-nous arrivés là ? "La faute à Voltaire »? Au moins peut-on affirmer que Voltaire, du haut de son immense autorité, ne cesse de louer en Racine l'écrivain plutôt que l'auteur dramatique. Si les œuvres de Racine dégageaient une charge émotionnelle sans pareil, c'était dû à la façon divine dont il maniait la langue française : "Je ne sais même si la langue française est susceptible d'une perfection supérieure à celle que Racine lui a donnée $»^{1}$. Chez Racine, Voltaire trouve toutes ces qualités qui manquent chez ce barbare de Shakespeare: unité de ton, vraisemblance, bienséance, équilibre, clarté, harmonie, naturel. Il en fait le symbole du classicisme le plus achevé au moment même où les Romantiques croient trouver en Shakespeare l'arme parfaite, et en Racine la cible rêvée. Ainsi naît le «Racine » qui nous est familier, modèle et contre-modèle, agrégat de qualités plus ou moins appréciées, qui devient au vingtième siècle un puits sans fond pour qui veut en tirer la preuve de sa propre théorie littéraire. Ce « Racine » est presque rassurant : objet inerte, figé sinon stérile, cadavre exquis toujours prêt à être découpé ou recomposé par chaque nouvelle génération d'anatomistes universitaires.

C'est beaucoup sur les épaules d'un auteur dramatique pour qui la notion même de "classicisme » était inconnue, qui a composé une série de pièces toutes différentes les unes des autres, n'en déplaise à ceux pour qui l'attribut « racinien » (néologisme créé par Voltaire) renvoie à des paramètres facilement

1. CEuvres complètes de Voltaire, édition Besterman (Oxford 1968-), D12387. 
identifiables ${ }^{2}$. Rappelons que le souhait le plus ardent de Racine était de plaire à son public: «La principale Règle est de plaire et de toucher. Toutes les autres ne sont faites que pour parvenir à cette première ». Dans cette Préface de Bérénice Racine enchaîne en s'adressant aux précurseurs de nos critiques universitaires : «Qu'ils se reposent sur nous de la fatigue d'éclaircir les difficultés de la Poétique d'Aristote. Qu'ils se réservent le plaisir de pleurer et d'être attendris ».

Pleurer et être attendris. C'est dire que le travail principal de Racine consistait à capter l'attention de son public, et à la retenir du début à la fin. Et ceci tout d'abord ni par une belle poésie ni des personnages intéressants, mais par une construction dramatique qui susciterait des émotions fortes. Dans sa première Préface de Britannicus, si souvent citée, il vante les mérites d'une action dramatique « qui s'avançant par degrés vers sa fin, n'est soutenue que par les intérêts, les sentiments, et les passions des Personnages ». L'idée même de la tragédie est inséparable de cet effet émotionnel et donc proprement dramatique. Avant donc de se lancer dans des thèses savantes sur le tragique (notion anachronique elle aussi, née au dix-neuvième siècle dans le sillage de la philosophie allemande), considérons au moins dans quel sens Racine employait ce même mot dans sa Préface d'Iphigénie:

Mes Spectateurs ont été émus des mêmes choses qui ont mis en larmes le plus savant peuple de la Grèce, et qui ont fait dire, qu'entre les Poètes, Euripide était

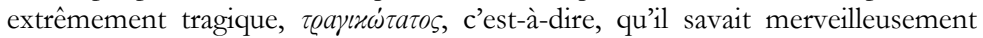
exciter la compassion et la terreur, qui sont les véritables effets de la Tragédie.

Ici Racine, si souvent accusé d'avoir bradé la gloire et la vertu cornéliennes pour l'amour et les larmes, ne disait pourtant rien de nouveau. Comme le note Georges Forestier, " tous les écrits théoriques de nos plus grands auteurs tragiques révèlent une attention primordiale à ce qu'ils jugent être au cœur de la tragédie : susciter l'émotion $»^{3}$. Nul doute alors que les émotions exprimées par les personnages, et partagées par les spectateurs, n'occupent la toute première place dans les tragédies de Racine. En d'autres termes, si nous sommes tous embarqués, pris par l'action dramatique, allant de l'avant, un peu dans le noir, comme les personnages eux-mêmes, c'est par le biais de l'émotion créée par la fabrication même de la pièce, par ce qu'Aristote appelle « l'agencement des faits en système » qui est «le premier et plus important des éléments de la tragédie $»^{4}$. Avant de chercher une quelconque « vision tragique racinienne », il serait donc utile de voir, sur un plan tout à fait pratique, comment Racine, artisan du

2. Cette thèse est développée dans notre Questioning Racinian Tragedy (Chapel Hill : University of North Carolina Press, 2005).

3. «Dramaturgie racinienne (petit essai de génétique théâtrale) ». Littératures classiques 26 (1996), p. 16.

4. Aristote, La Poétique, éditée par Roselyne Dupont-Roc et Jean Lallot (Paris, Seuil, 1980), ch. 6. 
théâtre, a construit chacune de ses tragédies pour émouvoir et ainsi tenir en haleine les spectateurs.

Ce court billet ne saurait tenter de décrire ces procédés. Notons pourtant avec quelle maîtrise Racine sait utiliser des recettes vieilles comme le théâtre : celle tout d'abord de mettre les personnages dans une situation de péril ou de défi, où tout est à gagner ou à perdre, et où le danger guette ceux mêmes qui n'en sont pas conscients. À partir de cette situation initiale, les émotions, suscitées par une incertitude et une menace toujours grandissantes, sont constamment intensifiées par une action où la pression du temps et de l'événement pèse comme un couvercle. Ces émotions sont donc suscitées, non pas par une quelconque crise métaphysique ou identitaire, mais par des situations incertaines, imprévisibles, et périlleuses qui se développent en se compliquant et s'intensifiant. Certes, l'ambiance oppressante ainsi créée s'est révélée être un terreau fertile pour l'imagination critique, mais elle représente tout d'abord une stratégie dramatique. Ce qui fait avancer l'action tragique, ce sont donc la puissance des émotions, ressenties par tous, et les réactions différentes et imprévisibles qu'elles provoquent, dans un contexte où l'ironie, enfant de l'aveuglement, fournit la musique de fond. Pensons à Iphigénie, nécessairement ignorante du projet meurtrier de son père, qui peut déclarer spontanément: "Quel bonheur de me voir la Fille d'un tel Père!» (v. 546). Au début elle n’a d'ailleurs qu'un seul sujet de crainte, celle de n'être pas admise au pompeux sacrifice qui se prépare, crainte qui provoque la réponse faussement limpide de son père, «Vous y serez, ma Fille» (v. 578). L'intensité sublime de ces paroles vient totalement de la situation dramatique dans laquelle elles sont prononcées. Voltaire, pour une fois au moins ouvert au travail proprement théâtral de Racine, sut les commenter avec émotion et bonheur :

Comment se peut-il faire qu'après cet arrêt de mort, qu'Iphigénie ne comprend point, mais que le spectateur entend avec tant d'émotion, il y ait encore des scènes touchantes dans le même acte, et même des coups de théâtre frappants? C'est là, selon moi, qu'est le comble de la perfection ${ }^{5}$.

Susciter l'émotion, dans une tragédie faite selon les règles de l'art au dixseptième siècle, implique une coexistence de tous les instants entre le nécessaire et l'imprévisible : construire une chaîne d'événements qu'on ne saurait prévoir, mais qui après coup, paraîtraient vraisemblables et inéluctables. Un exemple vient du début d'Andromaque, où Oreste expose ses options :

J'aime; je viens chercher Hermione en ces lieux,

La fléchir, l'enlever, ou mourir à ses yeux. (v. 99-100)

5. Euvres complètes, édition Moland (Paris, 1877-85), t. XVII, p. 411. 
Tous ces scénarios sont plausibles : aucun ne sera réalisé. Qui aurait pu prédire que l'ambassadeur des Grecs assassinerait le monarque auprès duquel il est envoyé, et ceci par désespoir, afin de gagner la main d'une femme qui, visiblement, le méprise ? La vérité - purement et délicieusement théâtrale - c'est qu'en tant que spectateurs, même si nous connaissons la pièce par cœur, nous ne savons pas, au moment de la représentation, ce qui va se passer. Rien n'est joué, rien n'est «fatal ». Même Phèdre peut à tout moment prendre des décisions autres que celles qu'elle va finalement prendre, allant jusqu'à laisser son mari envoyer à sa mort l'homme qu'ils aiment tous les deux avant tout. Incertitude, menace, suspense, péripétie, mélodrame même (le retour inattendu de Thésée, dans Phèdre, au pire moment possible) : Racine utilise ainsi toutes les ressources de l'art dramatique. Émotion garantie, pour peu qu'on puisse accepter qu'il écrit des pièces, et non pas des thèses.

Résumons : à une époque où nous autres universitaires gagnons notre vie à la sueur de nos théories, il est utile de rappeler que la priorité de Racine n'était pas de projeter une certaine vision du monde, mais de construire une action tragique capable d'engager le cœur et l'esprit du spectateur. Il le fait en représentant une action tragique qui suscite en nous des émotions exprimées dans une langue qui redouble leur intensité et leur beauté. Racine : auteur dramatique, d'abord et surtout. 